\title{
REFERENCES
}

Brattebö, G. \& Seim S. H. (1988) Teaching and training of invasive procedures on cadavers. Lancet ii, 1978-9.

Nelson M. S. (1990) Models for teaching emergency medicine skills. Annals of Emergency Medicine 19, 333-5.

Orlowski J. P., Kanoti G. A. \& Mehlman M. J. (1988) The ethics of using newly dead patients for teaching and practicing intubation techniques. New England Journal of Medicine 319, 439-41.

\section{Glucagon in the management of deliberate self-poisoning with propranolol}

Sir

The Logical treatment for an overdose of a $\beta$-adrenoceptor blocker would appear to be a $\beta$-agonist. However, in practice, enormous doses would be required (Critchley \& Ungar, 1989) and more conventional amounts of $\beta$-agonists therefore, do not restore the heart rate or blood pressure (BP) (Weinstein, 1984). Atropine or ventricular pacing may be tried, but in severe overdosage the myocardium becomes refractory to both pharmacological and electrical stimulation (Editorial B. M. J., 1978). Glucagon has been proposed as a more satisfactory treatment (Kosinski et al., 1971; Illingworth 1980; Weinstein, 1984) and its use in the management of an act of self-poisoning with propranolol is illustrated here.

The patient was a 55-year-old hypertensive female who was being treated with amitriptyline and propranolol. She took an excess of both of these drugs although the timing and magnitude of the overdose could not be established. On arrival? in hospital she was comatose with a sinus bradycardia of 58 beats $/ \mathrm{min}$, BP $165 / 80 \mathrm{mmHg}$ and a respiratory rate of 10 per min. Her blood sugar (Reflolux) was $6.5 \mathrm{mmol} / 1$. She did not have a stomach washout, presumably because of her comatose state. She was given intravenous naloxone $(0.4 \mathrm{mg})$, atropine $(0.6 \mathrm{mg})$ and glucagon $(1 \mathrm{mg})$, with no significant improvement.

On transfer to the High Dependency Unit her pulse rate was 52 beats $/ \mathrm{min}$ and BP $75 \mathrm{mmHg}$ systolic. Her arterial blood gases (on unrestricted oxygen) were $\mathrm{pO}_{2}$ $29.72 \mathrm{kPa}$ and $\mathrm{pCO}_{2} 5.84 \mathrm{kPa}$. Her serum urea and electrolyte concentrations were normal. Plasma propranolol concentration was not estimated. The 12 lead ECG met electrical criteria for left ventricular hypertrophy, but there was no disorder of conduction.

She was treated with intravenous fluids (11 N saline in $12 \mathrm{~h}$ ) and with larger doses of glucagon. There was a response within $2 \mathrm{~min}$ to an intravenous bolus dose of $4 \mathrm{mg}$ of glucagon with a maximum rise in heart rate to 60 beats $/ \mathrm{min}$ and in $B P$ to $134 / 84 \mathrm{mmHg}$. After $10 \mathrm{~min}$ the pressor effect of the injection began to wane and an infusion was prepared with $10 \mathrm{mg}$ glucagon in $100 \mathrm{ml}$ of $5 \%$ dextrose infused at $20 \mathrm{ml}$. The pulse rate and BP were recorded every $30-60 \mathrm{~min}$.

After $5 \mathrm{~h}$ with a pulse rate of approximately 60 beats $/ \mathrm{min}$ and a BP never below $120 / 60 \mathrm{mmHG}$ the glucagon infusion was stopped. At no stage were any arrhythmias or ectopic beats witnessed. With glucagon, the blood glucose concentration rose to 
$12.5 \mathrm{mmol} / \mathrm{l}$, falling to $5.9 \mathrm{mmol} / \mathrm{l}$ just before and to $1.8 \mathrm{mmol} / \mathrm{l}$ just after the infusion was terminated, when a $5 \%$ dextrose infusion was required to maintain normoglycaemia. The patient was fully conscious $24 \mathrm{~h}$ after the overdose with a heart rate of 72 beats $/ \mathrm{min}$ and a BP of $160 / 82 \mathrm{mmHg}$ and she made a complete recovery.

Betablockers bind to specific adrenoceptors to reduce the activity of adenylcyclase with a consequent fall in second messenger intracellular cAMP levels. This leads to alterations in the activity of regulatory proteins and the resultant cardiovascular effects. Glucagon acts either on a different receptor, or on a separate site on the adrenoceptor (Porte \& Halter, 1981; Kosinski et al., 1981) to activate adenylcyclase, causing a rise in intracellular cAMP levels by a mechanism independent of adrenergic effects. Therefore, glucagon has both chronotropic and inotropic effects (Westlie et al., 1971) which are retained in the presence of $\beta$-blockade (Glick et al., 1986).

The coma and respiratory depression which commonly occur with an overdose of propranolol may be due not only to its cardiovascular effects but also to its membrane depressant activity as more hydrophilic and cardioselective $\beta$-blockers rarely cause these additional problems (Critchley \& Ungar, 1989). However, in the present case, the patient had also taken amitriptyline.

Hypoglycaemia occurred after the glucagon infusion was abruptly discontinued. This was presumably due to high plasma insulin concentrations caused by the prior hyperglycaemia and depletion of liver glycogen stores, both induced by the glycolytic action of glucagon, together with blockade of adrenergically mediated counterregulation by residual propranolol.

The case confirms the efficacy of glucagon in the reversal of the bradycardia and hypotension following an overdose of a $\beta$-blocker. An initial intravenous bolus dose of $4-10 \mathrm{mg}$ is required, followed by a continuous infusion of $1-5 \mathrm{mg} / \mathrm{h}$ (the plasma half life of glucagon is about $5 \mathrm{~min}$ ). The use of glucagon rather than $\beta$ agonist may be particularly pertinant when the $\beta$-blocker is taken in combination with a tricyclic antidepressant or other proarrhythmogenic drug.

\section{P. I. MANSELL}

Department of Medicine, University Hospital,

Nottingham

\section{REFERENCES}

Critchley J. A. J. H. \& Ungar A. (1989) The management of acute poisoning due to beta-adrenoceptor antagonists. Medical Toxicology 4, 32-45

Editorial (1978) Self-poisoning with betablockers. British Medical Journal (i) 1010-1

Glick G., Parmley W. W., Wechsler A. S. \& Sonnenblick E. H. (1986) Glucagon. Its enhancement of cardiac performance in the cat and dog and persistence of its inotropic action despite beta-receptor blockade with propranolol. Circulation Research 22, 789-99

Illingworth R. N. (1980) Glucagon for betablocker poisoning. Lancet 11, 86 
Kosinski E. P., Stein N., Malindzak G. S. \& Boone E. (1971) Glucagon and propranolol (inderal) toxicity. New England Journal of Medicine, 285, 1325

Porte D. \& Halter J. B. (1981) The endocrine pancreas and diabetes mellitus. In: Textbook of Endocrinology. Williams R. H. (ed), chapter 15, pp 749. W. B. Saunders, Philadelphia, U.S.A.

Weinstein R. S. (1984) Recognition and management of poisoning with beta-adrenergic blocking $\equiv$ agents. Annals of Emergency Medicine 13, 1123-31

Westlie L., Andersen A., Jervell J., Rasmussen K. \& Storstein O. (1971) Cardiovascular effects of glucagon. Acta Medica Scandinavica 189, 179-84

\section{Is anaesthesia necessary for reducing shoulder dislocation?}

Sir

It is our experience that, provided it is performed gently and early enough, manipulation of the dislocated shoulder often does not require any adjunctive analgesia or anaesthesia.

The technique used for reduction is based on the Kocher manoeuvre. The $\stackrel{9}{9}$ patient is forewarned that no sudden movements will be used and that over a $\vec{\infty}$ period of $4-5 \mathrm{~min}$. the arm will be gently manipulated to allow relaxation of the $\frac{\mathbb{0}}{0}$ contracted muscle (i.e. subscapularis) that is keeping the humeral head in the $\frac{\mathbb{\Phi}}{3}$ dislocated position. No patient refused to undergo this manoeuvre, although $\underset{\Phi}{\mathbb{D}}$ several have expressed initial reservations. The patient is then seated on a pedestad, $\overrightarrow{0}$ with no back support, or on a chair ensuring that he or she does not leag \& backwards. An assistant gently supports the humeral head in the axilla, whies standing behind the patient and on the side opposite to the dislocation. The operator flexes the elbow of the injured arm and applies gentle longitudinal downwards traction on the humeral shaft. As traction is applied, gentle external rotation of the humeral shaft is performed. If successful, the humeral head invariably slips back into the glenoid cavity. Often, no definite jerk can be elicited as the shoulder reduces. Patients are invariably grateful once this is achieved.

In a 2-year period from April 11988 to April 1 1990, 44 acute anterior dislocations of the shoulder were treated in the Accident and Emergency Department at Walsall. The ages of the patients ranged from 17 to 90 . Of these, 34 were reduced without any adjunctive anaesthesia or muscle relaxant. Of those reductions that failed with the above procedure, 4 were reduced with the aid of intravenous diazepam and 6 required general anaesthesia. No neurovascular complications

were attributable to the reduction in any instance.
Although not widely accepted or recognized, it must be emphasized that the majority of shoulder dislocations can be reduced without any anaesthesia. This is particularly relevant if the patient is unfit for anaesthesia.

\section{A. BANERJEE}

Accident and Emergency Department

Manor Hospital

West Midlands 